\title{
Feasibility of Home-Based Attention Retraining On People with Mild and Moderate Traumatic Brain Injury
}

\author{
Aleena Maria Sunny ${ }^{1} *$
}

\section{ABSTRACT}

The aim of the study was to assess the feasibility of a 4-week home based attention retraining of people with mild or moderate traumatic brain injury. Purposive sampling was done to choose seven participants with attention deficit with mild or moderate traumatic brain injury as the sample of study. The Intervention consisted of tasks such as cancellation of letters, cancellation of symbols with distracters and dictation. Training in administering the intervention was given for patients as well as their caregivers. A baseline assessment for the above mentioned parameter and post-test assessment (after 5 weeks) were done on the participants to assess the impact of the intervention. The research design was informal experimental design before and after without control group. The post-test scores showed that the home based attention retraining has a positive impact on the attention of the participants. However, this couldn't be proved statistically because of its small sample size. The involvement of the caregiver as well as the motivation level of the participant was observed to have significant impact on the participants' performance along with several others. Home- based attention retraining was found to be effective, further rigorous studies with larger sample size and control group is suggested.

\section{Keywords: Brain Trauma, Retraining, Attention}

Incidence of traumatically brain injury, which is a traumatically induced physiological disruption in the brain function, has been at a hick due to the increasing automobile usage and ward across the world. A global perspective on the Indian Health Care System throws light to the likelihood neurological disability joining in as the third epidemic, largely due to the accelerated frequency of traumatic brain injury (TBI) in the country. Limited epidemiologic studies and lack of recent population-based data on traumatic brain injury in India limit ones understanding in this area. It is estimated that nearly 1 million persons are disabled annually. The rate of Road Traffic Accident (RTA) in ever increasing in the country out of which 60-70\% is of TBI in nature. According to the National Crime Records Bureau, India, for every RTA in the

\footnotetext{
${ }^{1}$ Research Student, Applied Clinical Psychology, Tata Institute of Social Sciences, Mumbai, India *Responding Author

(C) 2016 A M Sunny; licensee IJIP. This is an Open Access Research distributed under the terms of the Creative Commons Attribution License (http://creativecommons.org/licenses/by/2.0), which permits unrestricted use, distribution, and reproduction in any Medium, provided the original work is properly cited.
} 


\section{Feasibility of Home-Based Attention Retraining On People with Mild and Moderate Traumatic Brain Injury}

world there is at least twenty injuries that prevail. Accordingly in the year 2010 (the latest statistics) approximately 3.2 million serious RTA related injuries has occurred in the country. And this would lead to a rough approximation that nearly 3-3.5 million people have TBI due to all causes in 2010 in India. Hence every year our country generates approximately 1.5-1.7 million neurological disabled people only due to TBI.

With the advancements in the field of neurosurgery and acute trauma care, the mortality rates due to RTA has come down but the morbidity rates persist. As can be rightly mentioned, TBI can be considered as the leading cause of morbidity, mortality, disability, socio-economic losses and poor quality of life among survivors. Patients with mild, moderate and severe brain injuries suffer from physical, behavioral, emotional and social disturbances. Beside these issues persons with TBI experience serious long enduring problems with cognitive functioning (Upadhyay, 2008). Acquired brain injuries frequently produce difficulties in attention and short term memory along with problems such as low concentration, distractibility, forgetfulness, and difficulty doing more than one thing at a time (Hinkeldey \& Spellacy, 1990). Traumatic brain injuries (TBI) can have wide ranging outcomes including inattention and distractibility that significantly impair an individuals' performance in day-to day activities, as well as on tasks that demand new learning, calculations and verbal abstraction. Problems in attention and concentration, according to many neuropsychologists, always occur following a brain injury (Cicerone \& Keith, 2002). Both functional and organic illness can disrupt attention and cause failure in attention. Taking into account the concepts of cognitive rehabilitation and brain plasticity, early intensive interventions have proved to be successful; Home based attention retraining being one of it.

In order to study the impact of home based attention retraining in people with TBI, Glassgow Coma rating scale was used to screen people with mild-moderate TBI with the help of a neurosurgeon.

Seven participants, all educated at least upto pre degree was selected for the study. The study was a quasi- experimental research design with pre and post test; control group was absent. Digit Vigilance test was used to assess sustained attention and Triad test was used to assess divided attention and served as the pre-post tests, both tests are from the NIMHANS neuropsychological battery. The four weeks (seven days of the week) home based attention retraining was done; tasks involved were letter cancellation, symbol cancellation with distracters and dictation. Caregivers were trained to do the task on the subjects at home. Post test was administered to access the impact.

Descriptive Statistics was done to describe socio-demographic data and inferential statistics was done to check the efficacy of the intervention study. On Wilcoxon Signed Rank test was 


\section{Feasibility of Home-Based Attention Retraining On People with Mild and Moderate Traumatic Brain Injury}

statistically noticeable difference couldn't seen due to the limitation in sample size. However, individual analysis showed that there is betterment in the performance of all seven participants. The home based attention retraining has been found effective in the participants of the study. Along with the right conduction and monitoring of the tasks given several other factors came into the notice of the researcher which is significant. Level of motivation and involvement of the caregiver were prominent of them. Therefore, home based attention retraining was found to be feasible on people with mild and moderate traumatic brain injury.

\section{REVIEW OF LITERATURE}

Problems with memory, attention, executive function, behavioural control, and regulation of mood, associated with injury to the frontal and temporal lobes, are particularly troublesome. For its pervasive nature several studies have been conducted in the area of neuropsychology addressing the aftereffects of a traumatic brain injury, the findings of which are discussed below. According to Flerminger et.al (2005), regardless of the age of the patient, it is the changes in cognition and behaviour that represent the greatest burden to families after a traumatic brain injury. Difficulties with social skills may arise from deficiencies in self monitoring and social judgment. The studies conducted that take a look at mTBI from a neuropsychological point of view shows that there can be a high chance of developing deficits in cognitive functioning. De Guise, Feyz, Le Blane, and Richard Lamoureux (2005) assessed 348 TBI patients using Glasgow Coma Scale score and neurobehavioral rating measures score and found the cognitive deficits most frequently observed on the neurobehavioral rating were in the areas of attention, memory and mental flexibility as well as slowness and mental fatigability. Poor concentration can be attributed to reduced information processing capacity or reduced capacity for brain to carry on number of different operations at the same time (Gronwall, 1989). Similar study conducted on 37 mTBI patients showed deficits in speed processing, divided attention, working and long-term memory and executive function (Curtiss, Vanderlpeg, Spencer, \& Salazar, 2001). Another study conducted by Jonstone et. al in the year 1995 on 97 TBI patients found deficits in intelligence, memory, attention, speed of processing and flexibility. Another study by Bonnelle et.al referred to the failure in maintaining consistent goral-directed behavior as a result of TBI. Along with the above mentioned the impacts of a TBI are above the scope of discussion here. Undoubtedly, the need to identify functional impairment following a brain injury is critical to prevent re-injury during the period of recovery (Parker, Ostering, Donkelaar, \& Chou, 2005). Attention can be referred to the kind of concentration on a mental task in which you select certain kinds of perceptual stimuli for further processing, while trying to exclude other interfering stimuli (Strub \& Black, 2003). Attention can be of three kinds; (a) Focused attention is referred to as the concentration on one source of input to the exclusion of any other (Goldsten, 2008), (b) Sustained attention is attention for a prolonged periods of time (Sarter, Givens, \& Bruno, 2000) and (c) Divided attention is process of paying attention to 2 things at once so more tasks can be performed at the same time (Matlin, 1983). Even relatively small decrements in an individual's

(C) The International Journal of Indian Psychology, ISSN 2348-5396 (e) | ISSN: 2349-3429 (p) | 61 


\section{Feasibility of Home-Based Attention Retraining On People with Mild and Moderate Traumatic Brain Injury}

attention ability may significantly reduce the capacity for new learning and affect academic performance (Kinsella, Prior, \& Sawyer, 2007). Attention impairments frequently accompany executive dysfunction (Mateer \& Mapou, 2003).

Since the start of the era of Experimental Psychology the concept of attention is seen as the central to human performance and has been seen as a unified system for the control of mental tasks. Attention is a relatively basic cognitive function, according to Tsaousides \& Gordon (2009), disturbance in attention can exacerbate additional disturbances in executive function, communication and other relatively more complex cognitive functions as described in their study titled Cognitive Impairment following Traumatic Brain Injury. Even relatively minimal dearth in an individual's attention has the potential to result in long-term and may affect new learning. This holds true as the initial impairment potentially escalate the handicap. Attention deficits are prominent aspect of cognitive dysfunction after mild traumatic brain injuries. Cicerone, K. D. (1996) described how people after mTBI complain of distractibility and difficulty in attending to more than one thing at a time. Several studies in the area of neuropsychology attempted to study the impact of mTBI on focused, divided and sustained attention in particular. The findings of the study Reaction Time after Head Injury: Fatigue, Divided and Focused Attention and Consistency of Performance indicated that TBI causes slower information processing, deficits in divided attention and impairment of focused attention and therefore results in inconsistency of performance. The findings of another study conducted in 2003 examined the nature of attention disturbances on divided attention after mTBI were interesting. It was found that the attention deficits apparent during dual task demands may represent decreased cognitive efficiency which reflects mTBI patients' subjective complaints and functional impairments (Cicerone K. D., 1996). Similarly it was mentioned that poor sustained attention or alertness is a common consequence of TBI (Dockree, Bellgrove, Moloney, \& Carton, 2006).

The neurological basis for these attention deficits was explained in a study conducted by Arciniegas et. al in the year 2003. It was explained that impairments in attention have been well characterized in TBI, and are likely related to disruption of cholinergic functioning in the hippocampus; facilitation of learning, memory and other cognitive functions is the role of Acetylcholine. Additionally, disturbances in this neurotransmitter system may also account for disturbances in sensory gating and discriminative attention in this population (Arciniegas, Lawrenace, Topkoff, \& Cawthra, 2003). A predominantly right-lateralized front parietal network is often engaged during attention ally demanding tasks. Increase I $n$ the activation within the default mode network (DMN) is found to be associated with attention lapses(Bonnelle, et al., 2011). These changes in the neurology can result long term impact on individuals. The cognitive impairments following a TBI, as described by David et.al, which causes disturbances in attention, is found to be problematic. 


\section{Feasibility of Home-Based Attention Retraining On People with Mild and Moderate Traumatic Brain Injury}

\section{Sustained Attention}

Insufficient attention to tasks can result in slips of action as automatic, unintended action sequences are triggered inappropriately (Robertson, Manly, Andrade, Baddeley, \& Yiend, 1997). Such slips arise in part from deficits in sustained attention, which is the capacity to continue on a task which involves the avoidance of environmental distracters. Our ability to maintain a goaldirected focus without support from the environment requires the endogenous control of behavior (Dockree, Kelly, Roche, Hogan, \& Reilly, 2004); which is found to be compromised traumatic brain injury (TBI). TBI patients are particularly impaired at maintaining consistent behavioral performance and provide a unique opportunity to study the neural basis of sustained attention (Stuss, Stethem, Hugenholtz, \& Picton, 1989). In a study conducted by Whyte et.al in 1995 studied the neuro-anatomical as well as neuro-physiological reasons for the difficulty in doing tasks that require sustained attention. The results of this study which was experimental in nature found that the initial vigilance level of performance, vigilance decrement over time and accuracy was steeper in patients with TBI, hence providing a rationale for sustained attention retraining programs. A probe into tailor making the intensity based- treatment plans for the brain trauma can be sort from a study which made a comparison between patients with TBI and normal subjects demonstrated high correlation between the severity of brain trauma and the everyday attention failures reported. The negative correlation found between the performance of participants and Glasgow Coma Scores (Glasgow Coma Rating Scale is the tool used in this study) substantiate the findings. A relevant finding of this research conducted by Parasuranam et.al proved that during the first month after mild closed head injury, vigilance performance is unimpaired under normal task conditions, but may fall short under task conditions that require sustained effortful processing. Hence, there arises a question as to when should neuropsychological assessments be done so as to plan effective intervention strategies. The study by McAvinue et.al on error awareness and sustained attention on 18 TBI poatients and 16 matched control group is found to be relevant to this research. It was found that there is a reduced awareness of error during the sustained attention task given and that this ability is strongly correlated the sustained attention capacity. This significant link between the two process shows that feedback on error improves sustained attention performance of TBI participants (McAvince, O'Keeffe, McMackin, \& Robertson, 2005). Hence, suitable comments and criticisms on the performance on the tasks given can aid the betterment of patients with brain trauma.

\section{Divided Attention}

Division of attention could be an intermittent process in everyday life (Seema \& Rao, 1994). Multitasking has definitely become the pre-requisite for any successful task completion. Several studies conducted across the years has proved that deficits in divided attention is expected after traumatic brain injury. It is also proved that the severity of such deficits is positively correlated with the severity of the injury. The findings of a study conducted at 


\section{Feasibility of Home-Based Attention Retraining On People with Mild and Moderate Traumatic Brain Injury}

NIMHANS by Misra et.al showed that there is depleted attention resource allocation in mild head injury, and hence stressed on the need for compensatory effort from the patient to improve. Another interesting study found that people with TBI would still have problems in performing tow tasks dually even when they can perform well in these two tasks separately. A meta-analysis showed that this difficulty is more when such tasks require controlled processing, but not when there are carried out automatically. Thus, retraining is especially important in people who want to go back to works which requires intentional multitasking. However, there are studies that oppose these arguments. One such study is the only conducted by Azouvi et.al where the experimental group ( $\mathrm{N}=43$ people with severe $\mathrm{TBI}$ ) performed just as able as the control group in the task given. Surprisingly, higher level of mental effort was shown by the experimental group, which would explain why TBI patients frequently complain of mental fatigue. This subjective complaint seems to be relatively independent of cognitive impairment (Azouvi, Couillet, Leclercq, \& Martin, 2004). The aftereffects of divided attention deficits are not just restricted to attentional processes alone. The hypothesis that the deficits in episodic memory result from impaired attention allocation, it varies according to the injury severity and hence pronouncing the need to establish more sensitive anatomical and behavioral measurement at both acute and chronic stages of injury(Managels, Craik, Levine, \& Schwartz, 2002).

\section{Neuropsychological Assessments}

Brain plasticity can help people recover some lost abilities following brain injuries. Several studies suggest that early intensive interventions can result in dramatic improvements in the functioning of people with brain injuries (Geraldine \& Zanoli, 2003). Therefore, it can be inferred that acquired deficits of attention are treatable using specific-skills training. A neuropsychological assessment would highlight deficits of cognitive, emotional and behavioural functioning that are linked to structural abnormalities of different regions of the brain. Process training refers to a deliberate effort to employ a therapeutic program that would improve a wide range of tasks involving attention. Neuropsychological assessment in the early stages of recovery will facilitate awareness of the cognitive and behavioural consequences of the injury (Fleminger \& Ponsford, 2005). Further, there have been studies which have proved that cognitive impairments are still prominent in people who have apparently recovered after brain trauma. These can be found out only through the neuropsychological assessments which are apt to the individual. These impairments and deficits are seen as secondary to any brain damage by the scientific world. Cognitive rehabilitation (programs to help brain-injured or otherwise cognitively impaired individuals to restore normal functioning, or to compensate for cognitive deficits) may also be useful for the treatment of impaired attention, interpersonal communication skills, and executive function following TBI. This form of treatment is most useful for patients with mild to moderate cognitive impairments, and may be particularly useful for those who are still relatively functionally independent and motivated to engage in and rehearse these strategies (Tsaousides \& Gordon, 2009). Assessment of attention in particular severe multiple purposes 


\section{Feasibility of Home-Based Attention Retraining On People with Mild and Moderate Traumatic Brain Injury}

such as providing a comprehensive, initial baseline description of the patient, to quantify the level of deficits so as to track the development and to test the efficacy of the strategies used. The functional consequences to the victim of traumatic brain injury (TBI) can be severe. Intensive rehabilitative efforts typically emphasize the early phase and address mainly the accompanying functional deficits in the realm of basic activities of daily living and mobility. An otherwise successful medical rehabilitation may end unsuccessfully because of the failure to return to work, with profound consequences to the individual and family, both economic and psychosocial.

Home based attention retraining has reported to have improved performance on neuropsychological tests specific to attention (Hegde, Rao, \& Raguram, 2007). Sufficient evidence exists supporting the efficacy and effectiveness of cognitive rehabilitation, which has become the treatment of choice for cognitive impairments and leads to improvements in cognitive and psychosocial functioning (Tsaousides \& Gordon, 2009). There is an increased need to develop tailored interventions, and conduct more prospective studies in this area of psychology.

\section{Need of the Study}

The present study is an attempt to investigate the effect of attention process training program on the nature of attention impairments and see how it works on rate of attention development. People with mild traumatic brain injury usually go back to their premorbid life much earlier as compared to those with moderate and severe injuries. Therefore, they get back to their old routine, work or social life faster. Since attention is the very basic of all cognitive processes, people with traumatic brain injury would have to face difficulties in most of the day- to-day activities. This is particularly true in the case of mild traumatic brain injuries because, the intensity of the after effects of mTBI is not as pronounced as that of moderate and severe. There are a good number of people who refuse to take treatment for the difficulties they face. This study aims to investigate if the effectiveness of attention process training program can be a productive way of helping out numerous people who face difficulty in their day to day activities after mTBI. In other words, the study can be helpful in checking the extent of brain plasticity and scope on improvement for the population under study. The paucity of the studies in this area of research can be a reason that has resulted in not much people taking similar interventions. Therefore, this study can add into the pool of literature and hence is relevant.

\section{METHODOLOGY}

Aim:

The aim of the study is to assess the effectiveness of home based attention retraining of people with traumatic brain injury 


\section{Feasibility of Home-Based Attention Retraining On People with Mild and Moderate Traumatic Brain Injury}

\section{Objectives of the study}

1. To measure the base line scores of sustained and divided attention using the Digit vigilance test and the Triad test respectively.

2. To provide home based attention retraining for sustained and divided attention on people with mild or moderate traumatic brain injury

3. To check the feasibility of home based attention retraining for sustained and divided attention on people with mild traumatic brain injury

\section{Variables}

Independent variable: Home Based Attention Retraining

Dependent Variables:

1) Sustained attention

2) Divided attention

\section{Research Design: Quasi- Experimental research design}

\section{Operational Definition}

Mild Traumatic Brain Injury: a traumatically induced neurological disruption of brain function which has an initial Glasgow Coma Scale score of 13-15. Moderate Traumatic Brain Injury: a traumatically induced neurological disruption of brain function which has an initial Glasgow Coma Scale score of 9-12.

\section{Samples}

Sample size: 7

Sample: people with mild or moderate traumatic brain injury

Sampling: Purposive Sampling

\section{Inclusion Criteria:}

Individuals who score 13-15 in Glagow Coma Scale

Between 18-65 years of age. More than one month post injury (recovery period from any physical injury and internal distraction) Able to read and write English and Malayalam. Able to comprehend instructions

\section{Exclusion Criteria}

People with mild or moderate traumatic brain injury predominately in Temporal, Occipital or Parietal lobes

People with any other neurologic or psychiatric history 


\section{Feasibility of Home-Based Attention Retraining On People with Mild and Moderate Traumatic Brain Injury}

\section{Tools}

1) Screeing tool: Glasgow Coma Scale: The Glasgow Coma Scale (GCS) has been used for neurologic assessment of trauma patients since its development by Jennett and Teasdale. The scale assesses three aspects: eye opening responses, verbal responses and motor responses and depending on the scores obtained there are mild, moderate and severe traumatic brain injuries. Adequate inter-rater reliability and content validity has been established for GCS (Zasler \& Katz, 2001).

2) The pre and post test for attention are the Digit Vigilance Test (sustained attention) and the Triads Test (Divided attention). These are the tests for attention taken from the New NIMHAS neuropsychological battery developed by Rao SL, Subbakrishnan DK and Gopulkumar K in the year 2004.

Digit Vigilance Test: The test is developed by Lezak in 1995. The task is digit cancellation. The test takes about15 minutes.

The Triads Test: The test was developed at NIMHANS. It combines verbal triads with a tactual number identification test. The test takes 7 minute.

3) Home- based Attention Retraining: The Home- Based Attention Retraining is a 4-week intervention with 4 tasks which includes Simple letter cancellation, Complex letter cancellation, Symbol cancellation with distracters and Dictation. The number of errors committed by the participants is taken as the score.

\section{Statistics}

1. Descriptive Statistics: Socio-demographic data

2. Inferential Statistics:

Wilcoxon matched-pairs signed-ranks test: for the analysis of the pre and post test scores of Digit vigilance test and Trail making test

\section{Ethical consideration:}

The patient's consent will be sought

Permission from the hospital authorities will be sought

Confidentiality will be maintained

Participants can withdraw from the study any time they wished

\section{RESULTS}

This session details the result of data analysis of the chosen sample of participants. The first session looks at the description of the socio-demographic variables, the second session elaborates the task-wise trends seen in the scores obtained by the seven participants, the third session discusses the performance of each of the seven participant son the pre-test and post-test is 


\section{Feasibility of Home-Based Attention Retraining On People with Mild and Moderate Traumatic Brain Injury}

analyzed and the final fourth session mentions the relevant inferences gained from conducting inferential statistics for the variables from each tool.

\section{Socio-demographic details}

Twenty four people with mild or moderate traumatic brain injury had been identified for the study with the help of a medical practitioner. Sixteen of this number people were recognized to have attention deficits through the pre-tests. Only seven out of this sixteen completed the intervention programme and only the data of these seven has been retained. Their sociodemographic details are depicted in the given table.

As can be seen in the table, there were three females and four males whose ages ranged between 18 and 55 years. All were educated at least till higher secondary. Of these seven, only three were married.

Table 1, Socio-demographic details of the participants

\begin{tabular}{|c|c|c|c|c|}
\hline Participation ID & Age & Sex & Marital Status & Education \\
\hline A & 25 & $\mathrm{~F}$ & Single & Under graduation \\
\hline B & 26 & $\mathrm{M}$ & Single & Under graduation \\
\hline $\mathrm{C}$ & 22 & $\mathrm{~F}$ & Married & Under graduation \\
\hline $\mathrm{D}$ & 55 & $\mathrm{~F}$ & Married & Higher Secondary \\
\hline $\mathrm{E}$ & 18 & $\mathrm{M}$ & Single & Higher Secondary \\
\hline $\mathrm{F}$ & 40 & $\mathrm{M}$ & Married & Diploma \\
\hline G & 18 & $\mathrm{M}$ & Single & Under graduation \\
\hline
\end{tabular}

For formulation of the pre and post test, Digit Vigilance (Sustained attention) and Triad test (Divided attention) were used. In Digit Vigilance, scores were calculated on the basis of number of errors, which is the sum of the omissions and commissions by the patient. This can range from 0 to 313. As the score approaches zero, lesser is the deficit in the sustained attention. Similarly, on Triad test for divided attention, the range of the score is from 0 to 32 and, as in the case of digit vigilance, zero means no deficit in divided attention as assessed by the Triad test.

\section{Task- wise analysis}

Home based attention retraining was a 4-week intervention. The task given for the first 14 days was letter cancellation. The task involved cutting two given alphabets from the list of alphabets on each sheet every day. The number of letters and the size of the letters are inversely proportional to each other. That is, each day the size of letters is decreased and simultaneously, the number of letters (that can fit on a sheet) is increased. Thus, as the days of the intervention continue, the change in both size and number of letters that participants need to cancel leads to a 


\section{Feasibility of Home-Based Attention Retraining On People with Mild and Moderate Traumatic Brain Injury}

more sustained effort for a little longer each day. Difficulty level of the task also increases along with the days of intervention.

The caregiver was trained to invigilate the participant while helshe is doing the task. A track on the number of errors committed by the participant was kept. This was done by counting the number of omissions and commissions made by the participant. The caregivers were instructed to keep a record of the total time taken by the participant to finish the task, as this would help show if there is a difference in how participants perform in the post-test (versus their scores for the pre-test). However the researcher found that most of the caregivers failed to keep a note of this, hence that information couldn't be used.

For the ease of understanding and also for its complexity, the scores of the 2-week letter cancellation task is divided into two: for week 1(Day 1-7) the task is referred to as Simple Letter Cancellation and for the week 2 (Day 8-14) task scores are classified as Complex Letter Cancellation.

\section{1: Task: Simple Letter Cancellation}

The given graph represents the number of errors committed by the 7 participants on week 1 task of Simple Letter Cancellation. Interestingly, no participant showed a steady trend in the number of errors committed across the week.

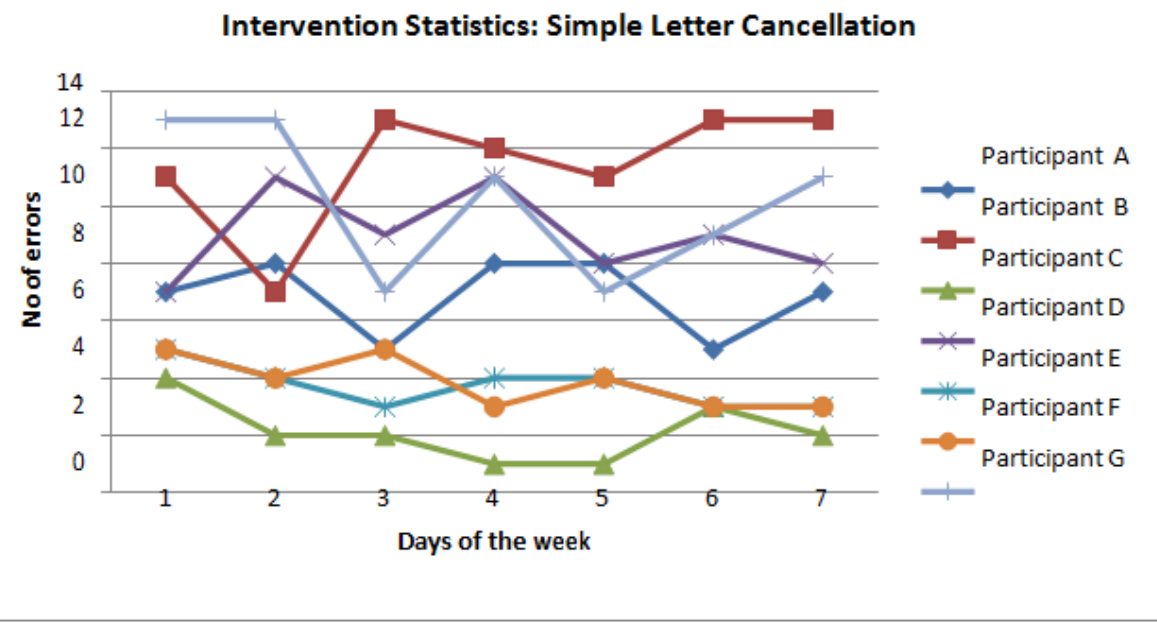

\section{Graph 2.1.1: The number of errors committed on Week 1}

As can be seen from the graph, each participant shows different patterns in the number of errors committed. Participant C, E and F have restricted all their scores within a limited range, which is below 6. While Participant A, B and G remained on the top half of the graph. Since this is the first task of the intervention, this can be used to understand the trend of the group $n$ terms of performance of different participants. 


\section{Feasibility of Home-Based Attention Retraining On People with Mild and Moderate Traumatic Brain Injury}

Table 2.1.1 The number of errors on each day of Week 1

\begin{tabular}{|c|c|c|c|c|c|c|c|c|c|}
\hline $\begin{array}{c}\text { Participation } \\
\text { ID }\end{array}$ & Day 1 & Day 2 & Day 3 & Day 4 & Day 5 & Day 6 & Day 7 & Range & Mean of errors \\
\hline A & 7 & 8 & 5 & 8 & 8 & 5 & 7 & $5-7$ & 6.85 \\
\hline B & 11 & 7 & 13 & 12 & 11 & 13 & 13 & $7-11$ & 11.42 \\
\hline C & 4 & 2 & 2 & 1 & 1 & 3 & 2 & $1-4$ & 2.14 \\
\hline
\end{tabular}

\begin{tabular}{|c|c|c|c|c|c|c|c|c|c|}
\hline D & 7 & 11 & 9 & 11 & 8 & 9 & 8 & $7-11$ & 9 \\
\hline E & 5 & 4 & 3 & 4 & 4 & 3 & 3 & $3-5$ & 4 \\
\hline F & 5 & 4 & 5 & 3 & 4 & 3 & 3 & $3-5$ & 3 \\
\hline G & 13 & 13 & 7 & 11 & 7 & 9 & 11 & $7-13$ & 10.1 \\
\hline
\end{tabular}

A comparison between the range of errors on day 1 (5-13) to that of day 7 (3-13) shows the limited impact of the task on the participants. Interestingly Participant B and Participant G are the ones who performance varied the maximum across the week. As can be inferred from the table, the number of errors varied across a range of $7-13$ for both the participants. On the other hand, Participant A, E and F remained more or less the identical with a range difference of 2 . There is a marked difference in the average number of errors committed by each participant, with Participant B has made the maximum number of errors across the week whose mean of errors is 11.42. On the other hand, with mean error of 2.14 it is the Participant $C$ made the minimal number of errors on week 1 .

\section{2: Task: Complex Letter Cancellation}

The second week of the 4-week intervention is Complex Letter Cancellation. The nature and kind of this task is similar to that of the Simple Letter Cancellation, but in this case the size of the letters and also their count increases as the days of the intervention. This requires the participants to prolong their attention as there is a simultaneous increase in the number of letters to be cancelled. Here too the error is calculated based on the number of omissions and commissions. 


\section{Feasibility of Home-Based Attention Retraining On People with Mild and Moderate Traumatic Brain Injury}

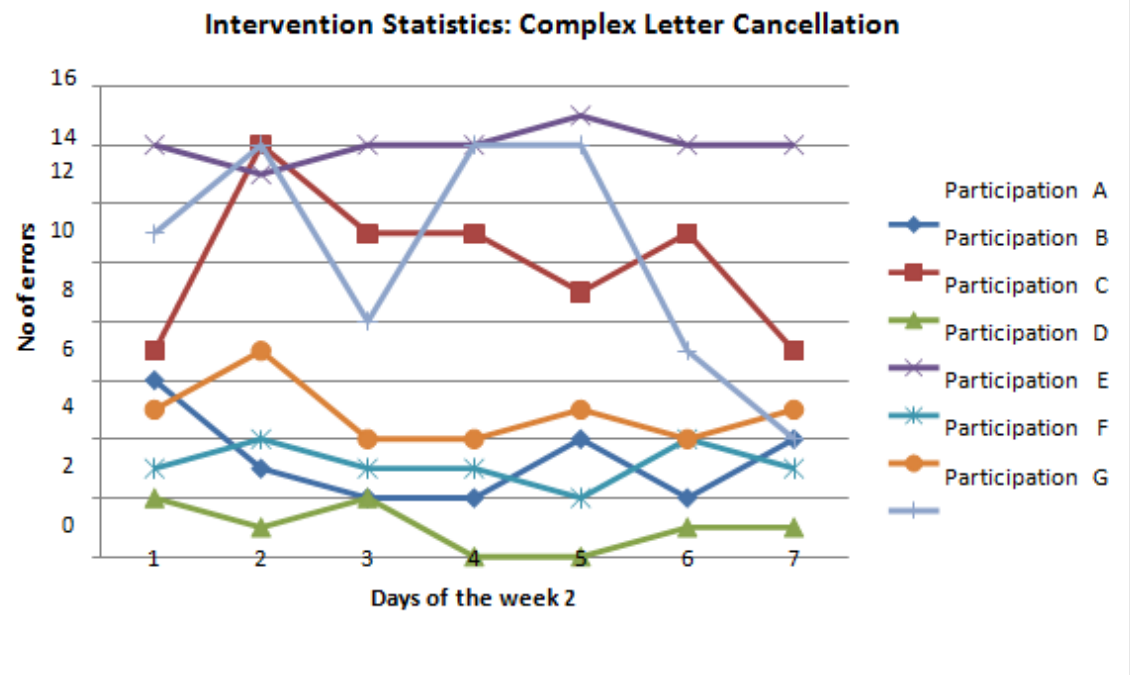

\section{Graph 2.2.1: The number of errors committed on Week 2}

The graph presented below represents the number of errors made by the sample across the seven days of Week 2. Here can be seen a noticeable difference in the performance of each participant. With reference to the graph, participants A C E and F remained more or less identical to each other with a steady error pattern. The performance of B, D and E varied drastically between and within each other. Participant $G$ has shown a drastic variation in the number of errors committed with scores taking evident hike and slump and then a sudden decrease in the number of errors made. The range difference for this participant was 10 and the mean of errors was 10.28. Participant B ( mean of errors = 10) also showed a similar trend as that of $G$ However, the highest number of errors was made by participant $D$ whose mean of errors was seen as 14 . As can be inferred from the given table this participant didn't not show much variance in performance and his score ranges between 13- 15 all throughout week 2.

Table: 2.2.1, The number of errors on each day of Week 2

\begin{tabular}{|c|c|c|c|c|c|c|c|c|c|}
\hline $\begin{array}{c}\text { Participation } \\
\text { ID }\end{array}$ & Day 1 & Day 2 & Day 3 & Day 4 & Day 5 & Day 6 & Day 7 & Range & Mean of errors \\
\hline A & 6 & 3 & 2 & 2 & 4 & 2 & 4 & $3-6$ & 3.28 \\
\hline B & 7 & 14 & 11 & 11 & 9 & 11 & 7 & $7-11$ & 10 \\
\hline C & 2 & 1 & 2 & 0 & 0 & 1 & 1 & $0-2$ & 1 \\
\hline D & 14 & 13 & 14 & 14 & 15 & 14 & 14 & $13-14$ & 14 \\
\hline E & 3 & 4 & 3 & 3 & 2 & 4 & 3 & $2-4$ & 3.14 \\
\hline F & 5 & 7 & 4 & 4 & 5 & 4 & 5 & $4-7$ & 4.85 \\
\hline G & 11 & 14 & 8 & 14 & 14 & 7 & 4 & $4-11$ & 10.28 \\
\hline
\end{tabular}




\section{Feasibility of Home-Based Attention Retraining On People with Mild and Moderate Traumatic Brain Injury}

Participant $C$ showed the least number of errors with scores ranging from $0-2$ as can be inferred for table 2.2. A more or less steady fashion was shown by rest of the participants (A, C, E, F) across the week and as can be referred in the graph 4.2.2, clustered at the bottom with minimal drifts.

\section{3: Task: Symbol Cancellation with Distracters}

The task for week 3 was Symbol Cancellation with Distraction. The principle behind this task is similar to that of letter cancellation, except for the change in the character used, i.e., instead of letters symbols were used. The difficulty level of the task also increase as the days of the intervention continues. In order to intensify the task, a distracter was added into the task. As in, the participants were asked to listen to any music of their choice simultaneously while doing the symbol cancellation. The music is expected to act as a distracter to the task and so the participants are expected to pay greater attention for the successful completion of the task.

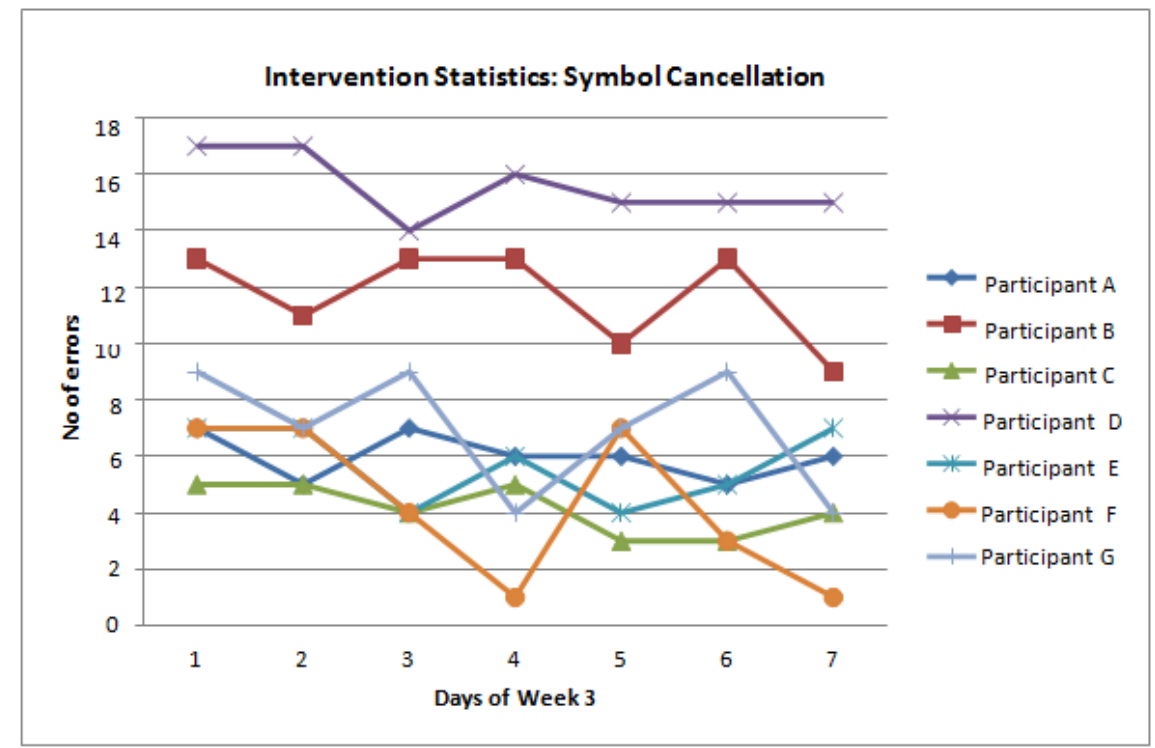

\section{Graph 2.3.1: The number of errors committed on Week 3}

The graph 4.2.3 gives an interesting outlook. There is a clear division between the performance of the participants. With reference to the given graph, there has been formed two kind of performance. One set consists of Participants A, C E F and G; clustering at the bottom of the graph with restricted range difference. As compared to their performance in the previous task, participants A C E and F remain consistent, while Participant G has also shown a reduction in the number of errors committed and joined the bottom of the graph. Listening to music didn't seem to have a pronounced impact on their performance as it remains more or less intact. Out of the above mentioned five participants, Participant $\mathrm{F}$ has shown the maximum fluctuations in their scores than anyone else, as can be inferred from the graph. 


\section{Feasibility of Home-Based Attention Retraining On People with Mild and Moderate Traumatic Brain Injury}

Participant B and D remained fixed at the top of the graph, indicating more number of errors and less improvement. Participant B who holds the second position from the top shows a gradual drop in the number of errors committed, while Participant D occupies the top most position with maximum number of errors $\mathrm{n}$ minimum change in their scores. More interestingly, this participant seemed to have reached a state where the error remains constant from day 5 onwards.

Table: 2.3.1 The number of errors on each day of Week 3

\begin{tabular}{|c|c|c|c|c|c|c|c|c|c|}
\hline $\begin{array}{c}\text { Participant } \\
\text { ID }\end{array}$ & Day 1 & Day 2 & Day 3 & Day 4 & Day 5 & Day 6 & Day 7 & Range & Mean of errors \\
\hline A & 7 & 5 & 7 & 6 & 6 & 5 & 6 & $5-7$ & 6 \\
\hline B & 13 & 11 & 13 & 13 & 10 & 13 & 9 & $9-13$ & 11.71 \\
\hline C & 5 & 5 & 4 & 5 & 3 & 3 & 4 & $3-5$ & 4.14 \\
\hline D & 17 & 17 & 14 & 16 & 15 & 15 & 15 & $14-17$ & 15.57 \\
\hline E & 7 & 7 & 4 & 6 & 4 & 5 & 7 & $4-7$ & 5.71 \\
\hline F & 7 & 7 & 4 & 1 & 7 & 3 & 1 & $2-7$ & 4.28 \\
\hline G & 9 & 7 & 9 & 4 & 7 & 9 & 4 & $4-9$ & 5.85 \\
\hline
\end{tabular}

The week-3 task produced an output in such a way that, the range difference was held small by all the participants, as compared to the previous two tasks. By referring to the table it can be seen that, Participant F has the maximum range (2-7) while Participants A (5-7) and C (3-5) have the minimum. However, the highest number of errors was committed by Participant $\mathrm{D}$ whose mean of errors is 15.57 with a range difference of 3 . It is inferred from the table that, there is a consistency in the errors of this participant, making him remains the one at the top of the graph. After him comes Participant B with a mean of errors as 11.71 Participant C and F remains more or less equal to each other with the mean error of scores being 4.14 and 4.28 respectively and the range difference being 2 and 6 respectively. They remained as the ones with least means of errors. Rest of the participants remained in between this range.

\section{4: Task: Dictation}

Dictation is the task on week 4 . The participants were given a set of 10 Malayalam words and a check on the spelling was made. One mistake in the spelling is marked as an error and then the total of those were taken. The range of errors was between 0 and 10 . That is 0 denotes no error, while 10 denotes the maximum. This same set of words was used of dictation throughout the time when the number of error was 1 . There were no fixed days for this assessment. The task 


\section{Feasibility of Home-Based Attention Retraining On People with Mild and Moderate Traumatic Brain Injury}

would come to an end on the day on which the participant's error score becomes 1 . Therefore, the number of days of intervention varied across the participants.

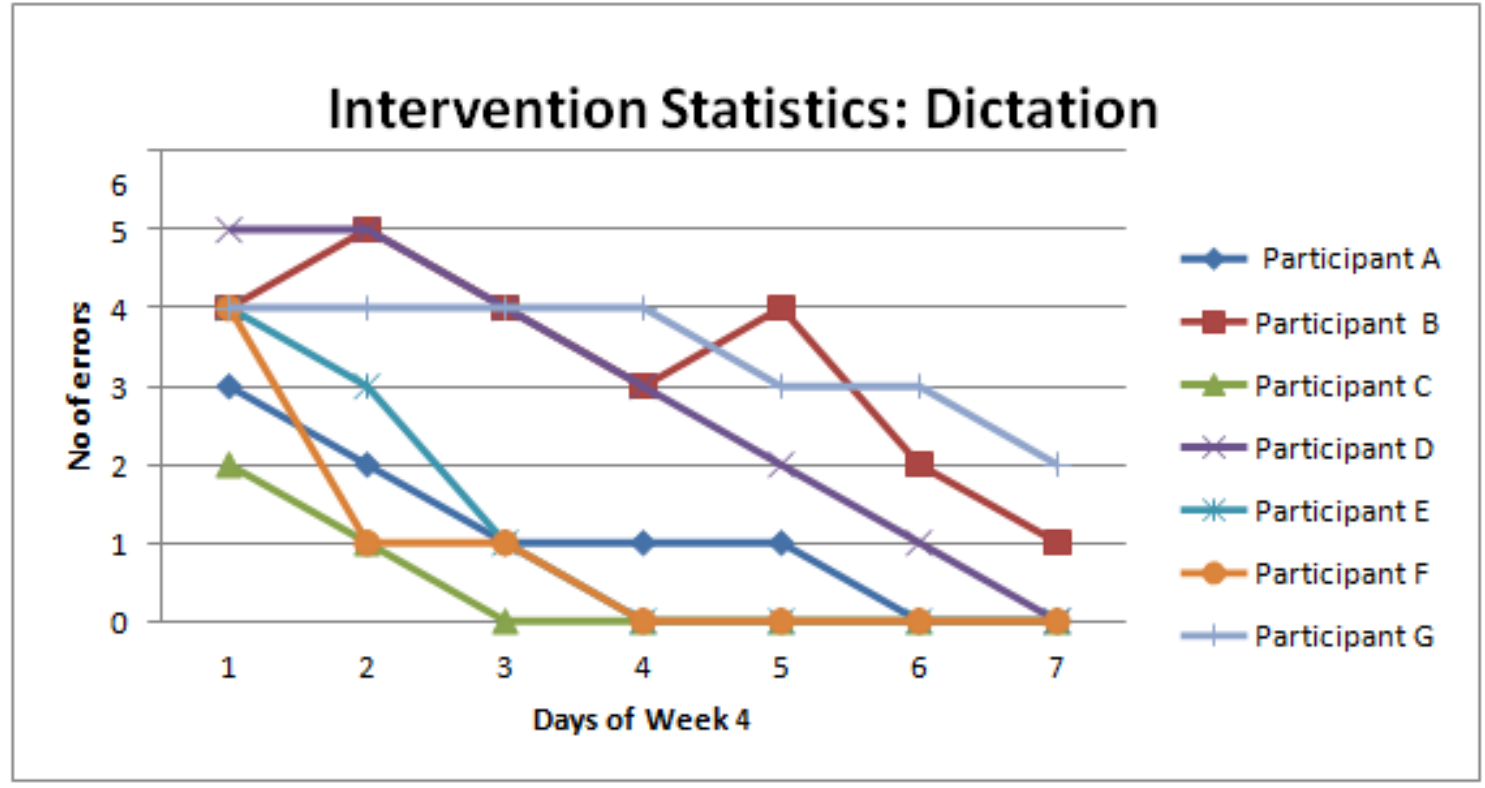

\section{Graph 2.4.1: The number of errors committed on Week 4}

Unlike all results of all the other three weeks, on this task the participants showed a similar trend: A trend of gradual decline. All participants except Participant $G$ attained the desirable 1 error within 7 days. In fact, five out of seven people had zero as their last score. With reference to the graph 4.2.4.1 participants A, C, E and F attained the expected 1 error within the first three weeks itself. It took more days for participants B and $G$ to reach expected error. Participant $G$ failed to achieve that score within a week's time.

Table 2.4.1 The number of errors on each day of Week 3

\begin{tabular}{|r|r|r|r|r|r|r|r|r|r|}
\hline $\begin{array}{r}\text { Participant } \\
\text { ID }\end{array}$ & Day 1 & Day 2 & Day 3 & Day 4 & Day 5 & Day 6 & Day 7 & Range & Mean of errors \\
\hline A & 3 & 2 & 1 & 1 & 1 & 0 & 0 & $0-3$ & 1.14 \\
\hline B & 4 & 5 & 4 & 3 & 4 & 2 & 1 & $1-5$ & 3.28 \\
\hline C & 2 & 1 & 0 & 0 & 0 & 0 & 0 & $0-2$ & 0.42 \\
\hline D & 5 & 5 & 4 & 3 & 2 & 1 & 0 & $1-5$ & 2.85 \\
\hline E & 4 & 3 & 1 & 0 & 0 & 0 & 0 & $0-4$ & 1.14 \\
\hline F & 4 & 1 & 1 & 0 & 0 & 0 & 0 & $0-4$ & 0.85 \\
\hline G & 4 & 4 & 4 & 4 & 3 & 3 & 2 & $2-4$ & 3.42 \\
\hline
\end{tabular}

(C) The International Journal of Indian Psychology, ISSN 2348-5396 (e)| ISSN: 2349-3429 (p) | 74 


\section{Feasibility of Home-Based Attention Retraining On People with Mild and Moderate Traumatic Brain Injury}

With reference to the table 2.4.1, it is participant B, D, F and G who have highest ranger difference, which is four, out of which, Participant B scored the highest mean of errors of all which is 3.28. This participant also showed occasional hikes in the error scores unlike others. At the same time, with a mean of errors as 0.42 Participant $C$ scored the least. More than that, Participant $\mathrm{C}$ is the one who had the minimum number of errors and showed the quicker improvement in limited span of time. Rest six of them had a similarity in their pattern with all of gradually reducing their error scores over the week.

\section{3: The pre-test and the post-test Analysis}

Table 3.1.1 Scores obtained by the participants on Digit Vigilance test for Sustained Attention pre and post the intervention.

\begin{tabular}{|l|c|c|c|c|c|c|}
\hline \multirow{2}{*}{ Participation ID } & \multicolumn{5}{|c|}{ Result of Digit Vigilance Test } \\
\cline { 2 - 7 } & Errors & Percentile & Time & & & Time \\
& & & & & \\
& & Scores & Taken & & Percentile & Taken \\
\hline A & 48 & 3 & 720 & 9 & 26 & 560 \\
\hline B & 44 & 3 & 660 & 18 & 11 & 560 \\
\hline C & 57 & 3 & 840 & 4 & 44 & 840 \\
\hline D & - & 3 & Couldn't & & & 720 \\
\hline E & 57 & 3 & 660 & 13 & 19 & 540 \\
\hline F & 39 & 3 & 780 & 22 & 20 & 660 \\
\hline G & 115 & 3 & 780 & 42 & 7 & 600 \\
\hline
\end{tabular}

Table 3.1.1 shows the comparison of scores obtained by the sample on their pre and post test. The scoring is done on the basis of number of errors committed by each participant and is matched with the corresponding scores on the scoring key. Scoring key has scores ranking from 3 to 100. Lower the score higher is the attention deficit. Anyone having a score of 3 is considered to have attention deficit, and as is evident from the table, only such people are included in the study. Therefore, all the seven participants of this study are people with attention deficit.

The table also shows the number of errors committed by the participants and their corresponding percentile scores on the post-test. It is very evident that they both share an inversely proportional relationship. That is, a decrease in the number of errors will result in an increase on the score. Or in other words, a high percentile score denotes that the participant has a made less number of mistakes. For instances, number of errors committed by Participant B is 18 and therefore, he got

(c) The International Journal of Indian Psychology, ISSN 2348-5396 (e)| ISSN: 2349-3429 (p) | 75 


\section{Feasibility of Home-Based Attention Retraining On People with Mild and Moderate Traumatic Brain Injury}

a percentile score of 11 . At the same time, the number of errors committed by participants $D$ and $\mathrm{G}$ is 42 and so they both scored 7 on their percentile score. All the other participants follow a similar trend.

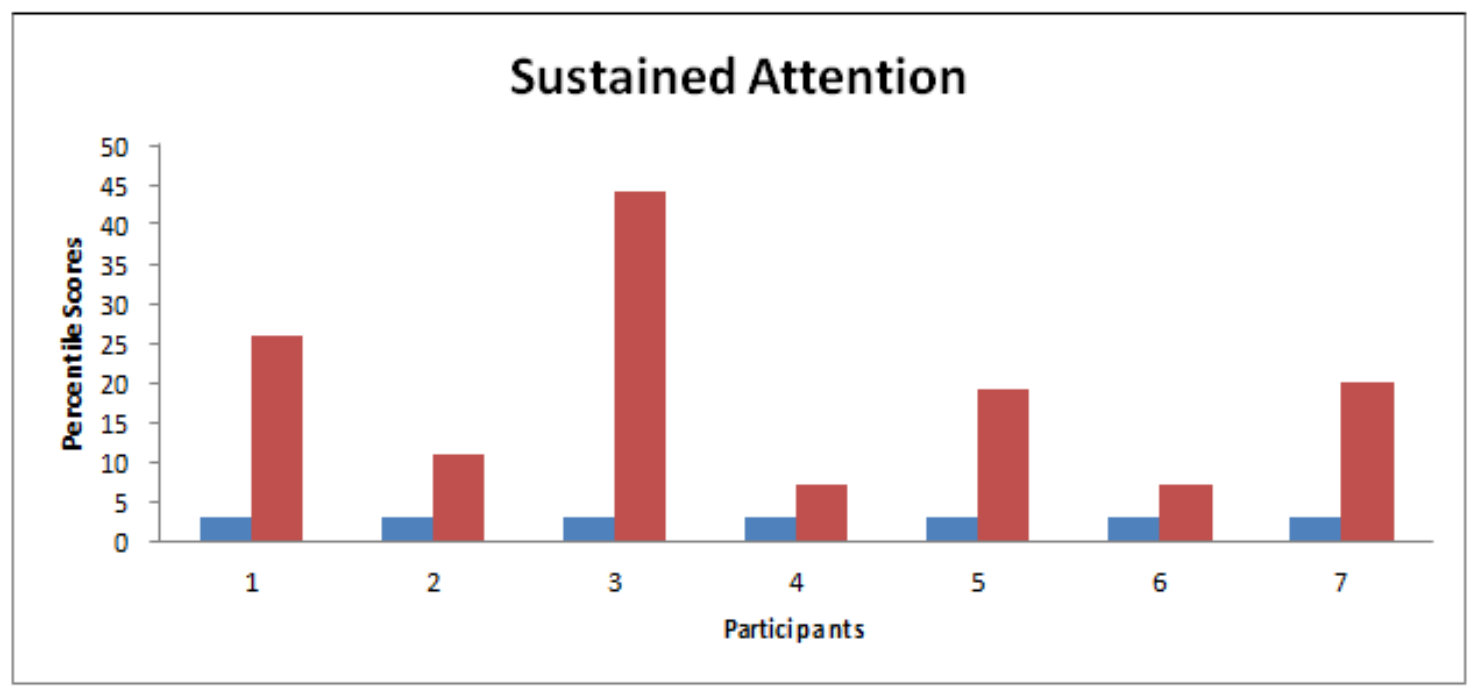

Graph 3.1.1: The percentile scores obtained by the participants on the Digit Vigilance for Sustained

\section{Attention for pre and post tests.}

Graph 3.1.1 shows how each of the participant have showed improvement in the scores obtained. All of them have shown an increase in the scores obtained, even though they some haven't shown a noticeable difference. As can be seen from the graph and the table, Participant $\mathrm{C}$ is the one who has the highest score and hence has shown remarkable improvement of all. Participants $\mathrm{D}$ and $\mathrm{G}$ have secured a score of seven in the post-test, which remains as the least of all scores. Remaining participants follow a similar trend and fit in between these two extremes.

\section{1: Triad test for Divided Attention}

As mentioned above here to people scoring below three for their percentile score are considered to have attention deficit and such people are included in the study. Therefore, the sample in this study scored three on the pre-test. Like in the Digit Vigilance Test, in Triad Test too, a low percentile score in the test would mean high number of errors committed. Or in other words, a person with high percentile score would be someone who committed lesser number of errors and there for problems with divided attention is supposed to be small. In case of this test, the percentile score can range between 3 and 100 . 
Feasibility of Home-Based Attention Retraining On People with Mild and Moderate Traumatic Brain Injury

Table 3.2.1: Scores obtained by the participants on Triad Test for Divided Attention pre and post the intervention.

\begin{tabular}{|c|c|c|c|}
\hline \multirow{2}{*}{ Participation ID } & \multicolumn{3}{|c|}{ Results of Triad Test } \\
\cline { 2 - 4 } & Pre-test & \multicolumn{2}{c|}{ Post-test } \\
\cline { 2 - 4 } & Percentile Scores & Errors & Percentile Scores \\
\hline A & 3 & 8 & 7 \\
\hline B & 3 & 7 & 15 \\
\hline C & 3 & 3 & 9 \\
\hline D & 3 & 9 & 9 \\
\hline E & 3 & 7 & 3 \\
\hline F & 3 & 9 & 11 \\
\hline G & 3 & 6 & 9 \\
\hline
\end{tabular}

Considering this wide range, the percentile scores obtained by each of the seven participants after post-test are restricted to the lower end. The highest of all is 15, which is obtained by Participant B, followed by Participant G whose percentile score is 11 . The highest number of errors is nine which is bagged by two participants $\mathrm{D}$ and $\mathrm{F}$ and hence remained with the percentile score of 3, indicating that the intervention didn't prove to have an impact on their divided attention. Remaining participants lie between this thin range of three to fifteen, which is not a good indicator on the intervention.

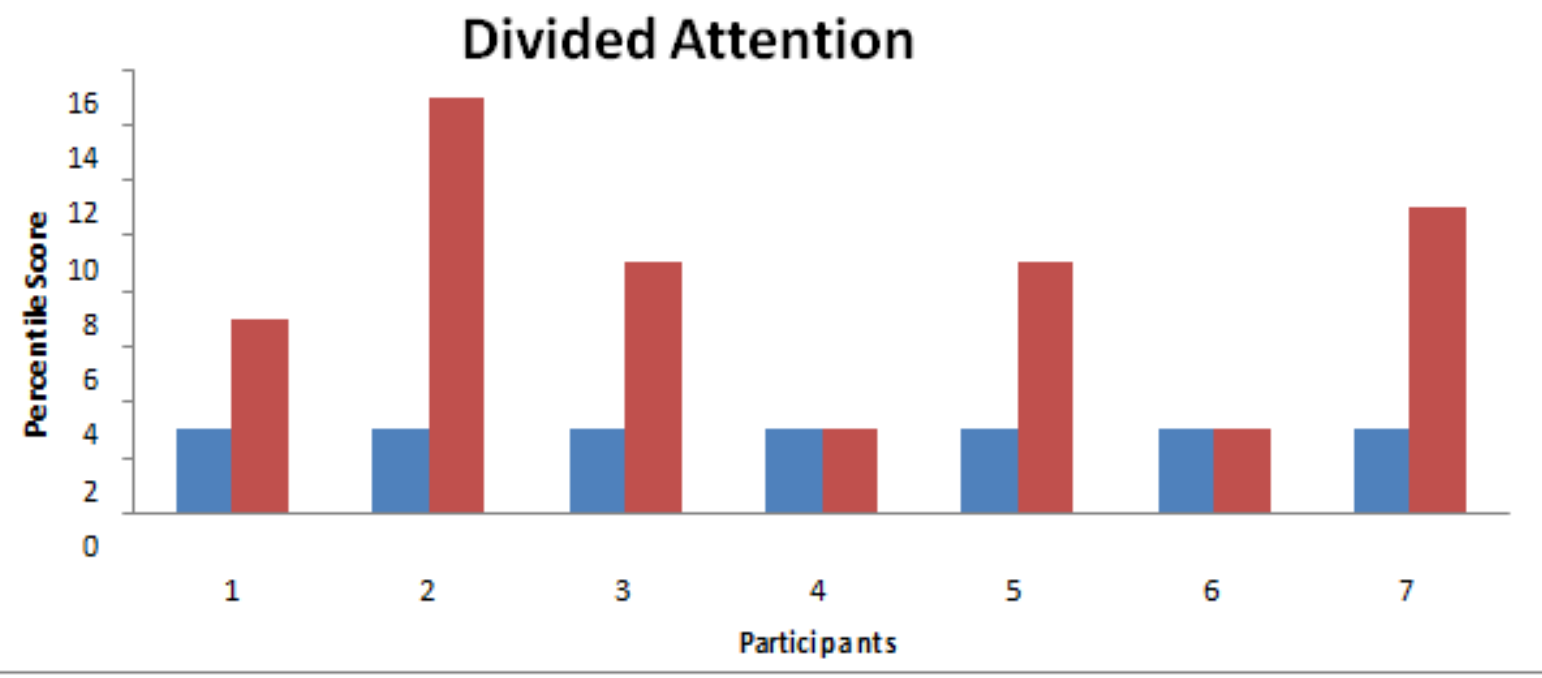

Graph 3.2.1: The percentile scores obtained by the participants on the Triad test for Divided Attention for pre and post tests.

By referring to table 4.2.2.1it can be seen that Participant B has secured highest score in this scale than anyone else. A small variation is shown in the score by rest of the participants. An 


\section{Feasibility of Home-Based Attention Retraining On People with Mild and Moderate Traumatic Brain Injury}

important thing to be noted here is that two participants out of seven didn't show any change in their score, which is an indication that this intervention didn't have an impact on them.

\section{4: Inferential Statistics}

In order to check for the statistical significance of the data available, Wilcoxon matched-pairs signed- ranks test was used in the study. The Table 4.1 the ranks obtained on Wilcoxon matchedpairs signed- ranks test and the test statistics of Wilcoxon matched-pairs signed-ranks test is shown by Table 4.2 .

Table 4.1, The ranks of Wilcoxon matched-pairs signed-ranks test

\begin{tabular}{|l|l|c|c|}
\hline \multicolumn{2}{|c|}{ Test Pairs } & Mean Rank & Sum of Ranks \\
\hline $\begin{array}{l}\text { Digit Vigilance Pre-test } \\
\text { \& Digit Vigilance Post- } \\
\text { test }\end{array}$ & $\begin{array}{l}\text { Negative ranks } \\
\text { Positive ranks }\end{array}$ & 3.50 & 10.50 \\
\hline $\begin{array}{l}\text { Triad test Pre-test } \\
\text { \& Triad test Post } \\
\text { test }\end{array}$ & Negative ranks & 3.50 & 10.50 \\
\hline
\end{tabular}

Here it can seen that the sum of positive ranks equals sum of negative ranks on both the tests.

Table 4.2: Test Statistics of Wilcoxon matched-pairs signed-ranks test

\begin{tabular}{|l|l|l|l|}
\hline Serial No & Variable: Attention & $\mathbf{z}$ Score & Significance \\
\hline 1 & Sustained Attention & 1.00 & Not Significant \\
\hline 2 & Divided Attention & 1.00 & Not Significant \\
\hline
\end{tabular}

$*_{\mathrm{z}} \leq 0.05$ is considered significant

The Wilcoxon Signed Ranks Test for matched pairs was used to assess whether sustained and divided attention of participants $(\mathrm{N}=7)$ with brain trauma were modified by giving them a 4week home based attention retraining based on the change between their before and after responses. The results revealed a statistically insignificant difference in their attention after the retaining where $p \geq 0.05$. The sum of both the positive and negative ranges for sustained attention pre and post test totaled as10.50, and that of divided attention is 14.0. Since sum of negative ranks equals to the positive ranks, the results revealed that participation in the home based attention retraining program did not have a positive impact on the attention of the sample. This interpretation stands true in the case of both sustained attention as well as divided attention.

\section{DISCUSSION}

For the commonly held understanding that medication and physiotherapy is all that is needed to treat someone with brain trauma, the individual as well as the family tend to give minimal importance to check on the cognitive capabilities of the affected. Despite the understanding and acceptance that an injury or a shock of any intensity to the brain has very chances of causing

(C) The International Journal of Indian Psychology, ISSN 2348-5396 (e)| ISSN: 2349-3429 (p) | 78 


\section{Feasibility of Home-Based Attention Retraining On People with Mild and Moderate Traumatic Brain Injury}

problems to the cognitive processes such as memory, language etc, the reluctance to take up help to improve these aspects after a brain trauma is surprisingly very limited. This can be seen as a major reason for the limited sample size. Of the sixteen people who were assessed to have attention deficits, only seven could complete the intervention. Lack of interest or motivation was found to be one of the key concepts that need to be discussed. Since there were only seven participants for the study, the researcher got the opportunity to observe and study them in greater detail than expected.

The first sample to be studied was Participant A, a 25 years old lady who is a nurse by profession. She met with a road traffic accident seven months (October, 2014) before the study and had frontal and prominent internal injury. She was found to be consistent in the scores she obtained each day throughout the 4 tasks she did. There was uniformity when it comes to each task she did. The number of errors she made remained more or less the same in the very first and very last days of the intervention. There was a noticeable difference in the scores of her post tests too, showing a significant improvement in the sustained attention. The researcher found her to be a motivated individual who was looking forward to get back her work as a nurse. She was interested in the tasks given to her. Moreover, her mother who was her primary caregiver was found to show genuine interest and involvement throughout the intervention, another driving factor that kept her motivation intact. In fact, she was the only participant who was keen on seeing her improvement on a daily basis, by have a record of the number of errors she committed each day. She made sure that she would meet the researcher every week and discuss about her improvements. Moreover, the researcher found the Participant and her caregiver to share a good bond with the researcher and could be seen to have an impact on the participant's performance. The researcher also found it easy to psycho-educate the participant and her caregiver about the importance such an intervention and also about doing similar tasks after the study too. The education background of the participant which is medical in nature could be a factor. Similarly, the age of the participant and her aspiration to be an earning- independent lady was pronounced throughout the span of time. Therefore, the age, education background, level of motivation, attitude of the caregiver and the relationship with the researcher were found to be significant in the performance of Participant A.

Participant B is a 26 years of old undergraduate male, who recently got back to work as a graphic designer. He met with a road traffic accident a month (May, 2015) before the first review by the researcher and was assessed to have moderate level of injury. As discussed in the chapter on results, he maintained evenness in the number of errors throughout the study. He was the one who scored highest in all the four weeks tasks and showed variations to a narrow extent. Also, he is only one who took seven days to complete the week-4 activity of dictation. His post test score on Digit Vigilance test which is used to assess sustained attention did show improvement but to a limited extent. However, he scored the highest on Triad test which is used to assess divided 


\section{Feasibility of Home-Based Attention Retraining On People with Mild and Moderate Traumatic Brain Injury}

attention. From the first day of review it wasn't easy for the researcher to psycho-educate the participant and his caregiver (who was the mother on the first day) about why such a task is important for him. Both of them seemed to be preoccupied with other aspects of treatment like medication and physiotherapy alone. This was made evident from the number of times alterations were made to the scheduled appointments to be matched with the ones of their physiotherapy, so that they didn't have to come for this alone. The inconsistency in the caregiver made it difficult for the researcher to discuss, validate and give feedback about his performance. It was his mother on the first week and so she was trained to do the intervention on him. The researcher never got a chance to meet her again, since his father came with him the next week. For the remaining three reviews the patient came by himself and so, the researcher faced limitation to deal with him. He got back to work as a graphic designer on the third week of intervention. This was when he said he found it difficult to do his work like before and spent some time with the researcher to know what all can be possibly done to get back to his previous state. While this can be seen as a progress, he had issues to find time to do the daily task because of his busy work timing. The researcher had to take effort to maintain professional boundaries with the participant as he was found to break them and know about the personal life of the researcher. However, this interest seemed to be one of the reasons that triggered him to finish the task. Therefore, in the case of Participant B duration of his illness, inconsistency and attitude of the caregiver, attitude towards the researcher, busy work life as well as the number of days post injury could be some of the points worth noticing here. However, the researcher couldn't come up with any logical reason to his improvement in the divided attention while his sustained attention didn't seem to have had a great progress. For these reasons, the researcher remains skeptical about his regularity in doing the task.

The 22 years old married under graduate lady is Participant C. She met with a road traffic accident two months (May, 2015) before the first review and was assessed to have mild traumatic brain injury at the start of the intervention. The number of errors she committed was small as compared to others and tended to gradually show a reduction in the number of errors over the simple and complex letter cancellation. However, she used to take long time to finish the task, but with minimum errors. On the third week, on the symbol cancellation with distracters task the number of errors increased and she was found to be irritated and annoyed. She scored the highest on the Digit Vigilance test which is used to assess sustained attention and is the one who showed the highest improvement as compared to others involved in the study. Her scores in divided attention also shows improvement, but not to a great extent. The researcher found her to be a short tempered person who gets easily irritated and annoyed. But at the same time, she seemed to be patient and inflexible until she finishes her task. This personality trait of her could be an important indicator of why her score has gone up in sustained attention and not so much of divided attention. Marital status also proved to be important here, as she is recently married and was helping her husband with their family business. She was motivated to go back to doing the 


\section{Feasibility of Home-Based Attention Retraining On People with Mild and Moderate Traumatic Brain Injury}

accounts of her husband's business. Her husband, who was constantly there as a caregiver was also a major source of support as he would make sure she does the task daily, counts the number of errors, discusses about her improvement and sort the researcher's help to find activities and task of similar nature even after the end of the intervention. May be for his knowledge or educational background or for his strong desire to see an improvement in Participant C, the caregiver made sure she gets everything she wants and it is his attitude that the researcher would appreciate the most in the case of Participant C. Therefore, the participant's personality traits, involvement of the caregiver, the caregiver's educational background, wish to go back to work, and marital status seemed to have involved in the betterment of Participant C.

Participant D is the 55 years old housewife who had the brain trauma due to a fall 6 months (April, 2015) before the first review. Her scores are the ones with maximum variations compared to all among the sample. The number of errors she secured was the highest of all in all the four tasks given to her. Her post tests scores made it evident that her improvement on sustained attention is very minimal and that she hasn't shown any improvement at all on divided attention. Participant D showed the least improvement of all in the study. Four days of the whole intervention she couldn't finish the task of the day and ended up handing over the incomplete sheets. Her daughter who was a nurse was her caregiver. Even though the caregiver was genuinely involved all throughout the intervention the researcher and the caregiver found it very difficult to motivate her and get her to do the task. There were times the researcher felt that the participant was just not trying at all. The participant used to angry with the increase in the number of letters to be cancelled each day and at times ended up not finishing the task. The caregiver also reported that it was very hard to make her do the work on the third week when distracters were involved and that she gets too fuzzy on those days. The researcher found Participant D got used to the way she is and was not looking forward for any improvement. Her age could be a reason. Basing on what the caregiver said, Participant D started enjoying the secondary gains that the status of being an ill person and so didn't want to show any improvement. Another point that came to the notice of the researcher is that the participant was preoccupied and sad that time for her daughter to return back to work was approaching. The researcher assumes that this would also have an impact on the participant's performance. Therefore, apart from the motivation level and age of the participant, attitude of the participant, the need to improve, the secondary gains of being ill and also the state of mind of the participant at the time of intervention seemed to have importance in the performance, despite having a healthy involvement of a caregiver.

Participant $\mathrm{E}$ is the youngest of the sample. He is 18 years old and the brain trauma was due to an accident that took place immediately after his 12th std board exam which was 3 months (April, 2014) before the first review for the intervention. He was assessed with moderate TBI and prominent internal injury along with the frontal lobe injury. The number of errors obtained 


\section{Feasibility of Home-Based Attention Retraining On People with Mild and Moderate Traumatic Brain Injury}

by him in the letter cancellation activity was small which ranged from 2 to 5 . But his scores have gone up when it came to symbol cancellation with distracters, but not too far. He finished the Dictation task in three days. His post tests scores shows improvement on both sustained and divided attention, but more in the former. He is the only child of his parents, of which his mother is the primary caregiver. He is from a lower middle class family and the researcher found that he was a studious student and has scored high grades for his higher secondary exams. Since he hadn't completely recovered from the injuries after the accident he have to miss a year of college and that has brought him great distress. This seemed to be a reason for his motivation to be cooperative to the researchers, do the task with interest. The caregiver was mostly sad and pessimistic about the full recovery of Participant $\mathrm{E}$ and this has somehow been communicated to the participant. The researcher found her to be over involved in the matters of the participant and this had caused irritation to the participant. She kept being so even after the researcher psychoeducated her about the repercussions this can cause in the performance of the participant. Along with the tasks of the intervention he was practicing other activities that would improve cognitive abilities such as Sudoku, letter cancellation from newspaper which would have improved his abilities further. Unlike others, the researcher could be there with him in person for two and a half week to monitor him doing the task. However, after getting discharged from the hospital his family found it difficult to reach the researcher due to the distance from their house to the hospital. Therefore, the researcher could go to their house and observe lot more, which would have strengthened his relationship with the researcher. Therefore, the financial status of the family, the over-involvement and pessimistic attitude of the caregiver about the recovery of the participant, the presence of the researcher as well as the accessibility to the researcher in terms of distance have been found to be crucial in the performance of Participant $\mathrm{E}$.

The 40 years old married male is Participant F. He is an auto driver and is educated up to Predegree. He is the breadwinner of the family and stays with his wife and 2 children. He met with the accident almost 9 months before and was assessed to have mild TBI at the time of first review. His errors are consistent in the first two weeks and increased on the third week, during which he stopped using distracters after the first two days of week three. However, he got done with the dictation on the second day itself. Pretest scores showed improvement in sustained attention. However, the intervention didn't prove to have an impact on divided attention and he remained to have divided attention deficit. Participant F came across as a hard working middle aged man trying to manage the financial burden of the family being the only bread winner. He was cooperative with the researcher to a certain extent. The researcher found him sharing his personal issues such as those with the family and financial trouble etc with her more than his improvement due to the intervention. There were times when the researcher felt that he didn't give importance to his condition after the trauma or about the intervention. There was once when he said, such minute things don't matter, when he had lot more things to worry about. The researcher felt that he finished the intervention for the relationship he built with the researcher, as 


\section{Feasibility of Home-Based Attention Retraining On People with Mild and Moderate Traumatic Brain Injury}

he was having a weekly venting out session. He didn't have a caregiver to come with him or to invigilate his tasks. He never brought anyone along even after constant reminders. Lack of time was a major problem he had to face due to busy work life. The researcher is left wondering why he still managed to still come to her even without finishing the weekly task or without any interest in seeing an improvement. Therefore, absence of caregiver, lack of time, lack of concern about his own condition, financial burden and relationship with the researcher is found to affect the performance of this participant.

Participant $\mathrm{G}$ is an 18 years old male Under graduation student who had the brain trauma 10 months (November, 2014) before the start of the intervention. He had been undergoing Physiotherapy since then. His mother is his primary caregiver, along with his father and elder brother. His scores remained high throughout the intervention as discussed in the previous chapter. He is one who showed maximum fluctuations and inconsistency in scores. On the task Dictation, even after seven days he could not reach the preferred score of one. His post-tests scores showed improvement, but not to great extent. The score shows that he has showed improvement on divided attention than the sustained attention. The researcher found him to be least interested in the intervention. So was his family. Both the participant and his family were cold to the researcher and she found it difficult to make them understand the importance of such tasks in his faster recovery. Both the parties were concerned about the physical improvement and approached the researcher as if task is of use only for the researcher and not for them. Therefore, the lack of interest, need and motivation are the crucial factors in his performance.

On the whole, greater degree of improvement was shown by the participants in sustained attention assessed using the Digit Vigilance test than divided attention assessed using Triad test. One reason for this is the nature of training given to the sample. The tasks of the activities were majorly to cancel letters and symbols in order to increase the attention span of the sample. This resembles that of the digit cancellation task of the Digit Vigilance test. That is the test and the tasks resembled each other and hence, it is natural for the participants to gain mastery over such a task by repetition and familiarity. The only task that trained the participants in division of attention was the week three activity which is symbol cancellation with distracters. This would be rationale for the reduced performance on divided attention. Even then, there are participants who showed increase in their performance on the assessment of divided attention too. This can also be seen as a shared impact of training in sustained attention on divided attention.

However, the intervention was statistically proved insignificant. The small sample size is seen as the major reason for this. Taking into account the score obtained by each of the seven participants in post- tests, the intervention does have a positive impact on the betterment of attention of the participants in the study. The researcher feels that if sample size was high, the intervention would have shown a statistical significance on improving the attention of people 


\section{Feasibility of Home-Based Attention Retraining On People with Mild and Moderate Traumatic Brain Injury}

with traumatic brain injury. Limited sample size, absence of a control group, and lack of variety of tasks given are a few of the limitation of the study.

\section{Researcher's Observation}

Several factors were found to have an impact on the performance of TBI patients in the current. Apart from the efficacy of the intervention several other factors also found to be important which is shown in the diagram represented below. For the ease of understanding, the researcher has categorized the factors under three broad areas namely, neurological, psychological and socioenvironmental. The factor that was found to be relevant by the researcher was supported by relevant researches in the area.

Among the neurological factors severity of the injury was found to be relevant. Out of the seven samples, three were of moderate level of severity and showed least amount of betterment.

Motivation level was something that was found to be of great impact. Those who were motivated themselves or was motivated by the researcher or caregiver has proved to be efficient in the task. Motivating Level of motivation and emotional stress were found to be significant which is substantiated in the study conducted in 1996, which claimed that the dysfunction in the dopamine activity post-trauma is the cause of poor motivation in patients with brain injury. This can lead to associated deficiencies in reward responsiveness and frontal cognitive function of which attention is one. A study was conducted by Fleming et.al, on the relationship between self awareness, emotional distress, motivation and outcome in adults with TBI. Self-awareness after brain injury is associated with greater motivation to change behavior and higher levels of depression and anxiety (Fleming, Jennifer, Strong, \& Roderick, 1998). Substantial studies in this area were backed up by the finding of the current studies also.

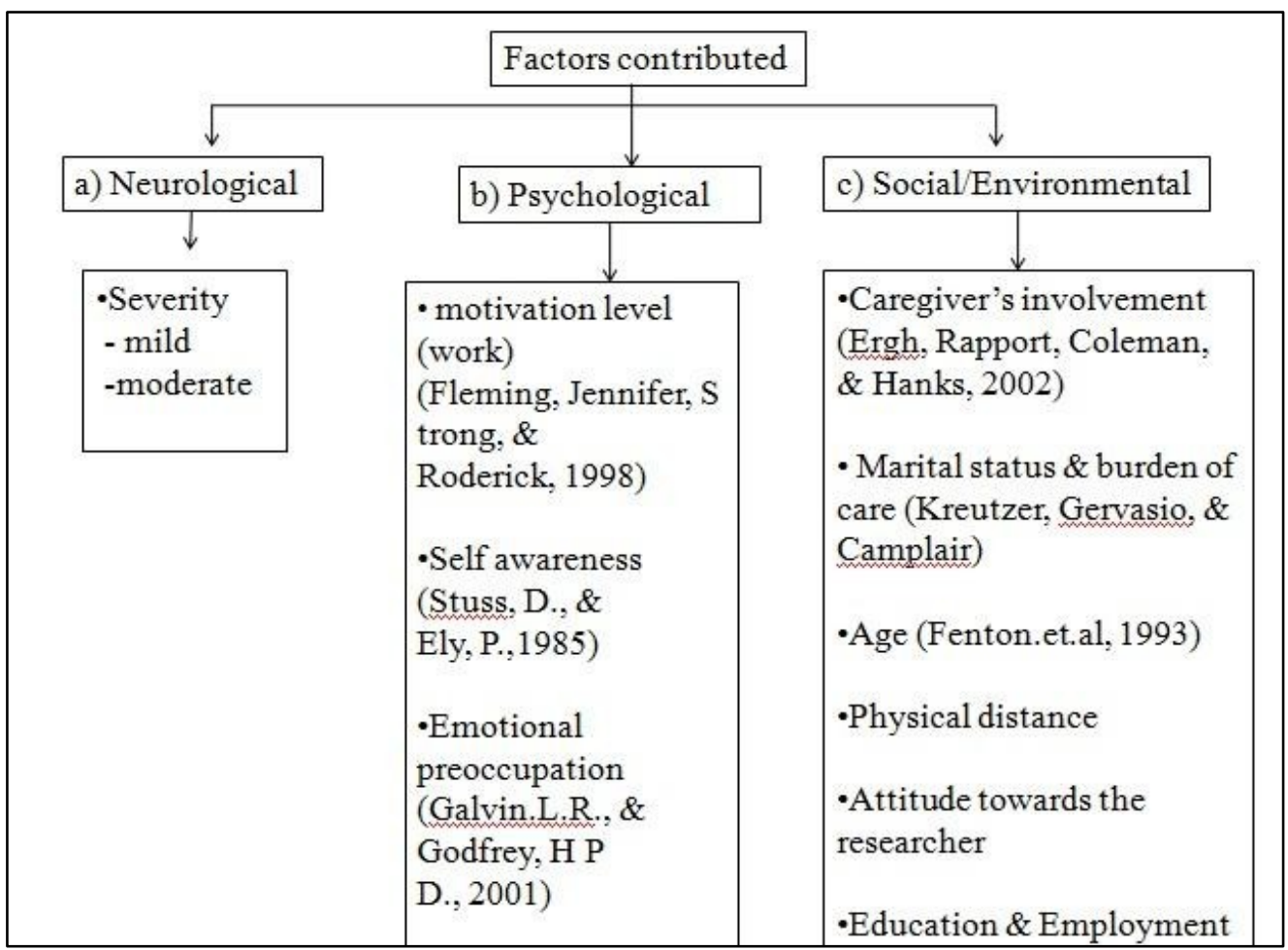

(C) The International Journal of Indian Psychology, ISSN 2348-5396 (e)| ISSN: 2349-3429 (p) | 84 


\section{Feasibility of Home-Based Attention Retraining On People with Mild and Moderate Traumatic Brain Injury}

Similarly another key factor that came up in the current study is the impact of caregiver in the performance in cognitive tasks of the TBI patients. A study that investigated the prevalence of psychological distress and unhealthy family functioning among primary caregivers indicated that feeling of burden and alienation is commonly reported. The much likely outcome of this, depression, was prominent among spouses compared to parents in the task of care giving. This finding further substantiated the current study that betterment were shown by patients whose caregivers were parents than those whose were their spouses. (Kreutzer, Gervasio, \& Camplair). Hence, psychological wellbeing of primary caregivers is crucial in the treatment. But how feasible it is to expect the caregiver to unconditionally involve into the treatment is the question here. This particularly is relevant as the physical impairment, number of behavioural problems (which according to Marsh et.al are patients' emotional difficulties, anger, apathy and dependency) and social isolation. Adding to this, more than half of such caregivers reported poor social adjustment (Marsh, Kersel, \& Havill, 1998). Moreover, distress among caregivers and family members of persons with TBI may stress the entire family system, including the person with injury. Strained relationships, disruption of family roles and communication, delays in rehabilitation and adjustment, and decreased willingness of caregivers to continue to care for the person with injury at home are common in these families (Ergh, Rapport, Coleman, \& Hanks, 2002). Despite all these, there are studies which proved that caregivers report higher levels of satisfaction than dissatisfaction with their caregiver roles and hence, adequate family support is relevant for successful coping. It is impossible to generalize the various personality disturbances post the injury because of the varying nature and position of the brain lesion.

The researches further suggested the need to tailor make the rehabilitation timing and approach to match the individual's level of self awareness, motivation and emotional distress. Increasing self awareness seems to have an automatic effect on the motivation levels and state of mind of the patients. As understood from the current study, people who seemed to have high levels of motivation showed improvement post neuropsychological intervention while those who were emotionally preoccupied didn't show much progress. Hence, the key to induce motivation (which was found to be difficult in the sample) is to give opportunity for self awareness. There appears to be a complex interaction between pre-morbid characteristics, injury factors, post injury impairments, personal and environmental factors in TBI patients, which influences "return to work" outcomes in ways that make prediction difficult. Injury severity and lack of self-awareness appear to be the most significant indicators of failure to return to work. A significant proportion of TBI patients, including those who are severely injured, are able to return to productive employment if sufficient and appropriate effort is invested (Shames, Treger,

\& Ring, 2007). A comprehensive approach-medical and psychosocial-eventually entailing adequate vocational rehabilitation with supported employment can improve outcomes. 


\section{Feasibility of Home-Based Attention Retraining On People with Mild and Moderate Traumatic Brain Injury}

\section{CONCLUSION}

The home based attention retraining has been found effective in the participants of the study. Along with the right conduction and monitoring of the tasks given several other factors came into the notice of the researcher which is significant. The age, education background, marital status, employment and level of motivation, interest and need of the participants, the presence or absence of caregiver, attitude of the caregiver, attitude towards the researcher, duration of the illness condition, the participants' state of mind, his or her personality characteristics, the financial status of the family, duration of the researcher's presence, education background and age of the caregiver, the importance given to the recovery as well as the accessibility to the researcher in terms of distance have impacted the performance of the participants. While a good bond with the researcher has proved to be beneficial to the participant's performance, inconsistent caregiver, lack of need, interest and motivation of the participant, the reinforcing effect of the secondary gains of illness, over-involved and pessimistic caregiver has reduced the performance rate of the participants in the study.

Greater improvement is seen on sustained attention than divided attention. The resemblance of the tasks given to the task used in the assessment of sustained attention could be the rationale of this. What so ever it is, the intervention seems to have a positive impact on both divided and sustained attention of the sample. However, the intervention was statistically proved insignificant for the small sample size.

\section{REFERENCES}

Arcinegas, D., Adler, L., Topkoff, J., Cawthra, E., \& Reitie, M. (2003). 1-13.

Arciniegas, D., Lawrenace, A., Topkoff, J., \& Cawthra, E. (2003). Subject Review: Attention and memory dysfunction after traumatic brain injury: cholinergic mechanisms, sensory gating, and a hypothesis for further investigation. 1-13.

Azouvi, P., Couillet, J., Leclercq, M., \& Martin, Y. (2004). Divided attention and mental effort after severe TBI. Neuropsychologia, 1260-1268.

Bonnelle, V., Leech, R., Kinnuene, K. E., Ham, T. E., Beckmann, C. F., Boissezon, X. D., . . . Sharp, D. J. (2011).

Default Mode Netwrok Connectivity Predicts Sutsianed Attention Deficits after Traumatic Brain Injury. The Journal of Neuroscience, 13442-51.

Cicerone, \& Keith. (2002). Remediation of working attention in mild traumatic brain injury2002. Brain Injury, 185-195.

Cicerone, K. D. (1996). Attention Deficits and Dual Task Demands after Mild Traumatic brain Injury. 10(2), 79-90. Curtiss, G., Vanderlpeg, R. D., Spencer, J., \& Salazar, A. M. (2001). Patterns of verbal learning. Interntaional Jounral of Nueroupsycholgy Society, 5740585.

DasGupta, J. (2003). A study to examine the validity of tests of attention, learning and memory. Bangalore: NIMHANS . 


\section{Feasibility of Home-Based Attention Retraining On People with Mild and Moderate Traumatic Brain Injury}

D'Elisa, L. F., Satz, P., \& Uchiyama, C. L. (1996). Colur trails tests. USA: Psychologica lAsssessment resources, Inc.

Dockree, P. m., Kelly, S. P., Roche, R. A., Hogan, M. J., \& Reilly, R. B. (2004). Behavioural and physiological impariments of sustained attention after traumatic brain injury. Cognitive Brain Research, 403-414.

Dockree, P., Bellgrove, M., Moloney, P., \& Carton, S. (2006, July 26). Sustained attention in traumatic brain injury (tbi) and healthy controls: enhanced sensitivity with dual-task load. Experimental Brain Research, 168(1-2), 218-229.

Dugbartey, A. T., Townes, B. D., \& Mahurin, R. K. (2000). Equivalence of the Color Trails Test and Trail. 425-431: Equivalence of the Color Trails Test and Trail.

Elkin-Franstona, S., Lebowitza, B. K., Lissa, R., Kapusta, B., Hollisa, A. M., \& O'Connora, M. C. (2007). The use of the Color Trails Test in the assessment of driver competence: Preliminary report of a. Archives of Clinical Neuropsychology, 631-632.

Ergh, T. c., Rapport, L. J., Coleman, R., \& Hanks, R. (2002). Predictors of caregiver and family functioning follwoing TBO: Social Support Moderates caregiver distress. Jounral of Head Trauma Rehabilitation, 155-174.

Fan , J., McCandliss, B. D., Sommer, T., Raz, A., \& Posner, M. I. (2002). Testing the efficency and independce of attentional networks. Jounral of COgnituve Neuroscience, 340-347.

Fleming, Jennifer, M., Strong, J., \& Roderick. (1998). Cluster analysis of self awreness levels in adults with traumatic brain injry and relationship to outcome. Jounral of head trauma rehabiliataion.

Fleminger, S., \& Ponsford, J. (2005, December 17). Long term outcome after traumatic brain injury: More attention needs to be paid to neuropsychiatric functioning. 1419-1420.

Geraldine, D., \& Zanoli, K. (2003). Early intervension and brain plasticity. Jounral fo Human Developemnt and Disability.

Goldsten, B. E. (2008). Cognitive Psychology. New York.

Gronwall, D. (1989). Cumulative and Persisting Effects of COncusion on Attention and COgnition:mTBI. 153 -162. Hedge, S., Rao, S. L., \& Raguram, A. (2012).

Hegde, S., Rao, S. L., \& Raguram, A. (2007). Integrated Psychological Intervension for Schizophrenia. The international Jornal of psychosocial rehabilitation , 5-18.

Hinkeldey, N. S., \& Spellacy, F. (1990). The structure of head injury patients behavioural complaints:A preliminary study: Brain Injury. Brain Injury, 115-134.

Johnstone, B., Hexum, L., \& Ashkanazi, G. (1995). Extent of COgnitive Decline in Traumatic Brain Injury Based on Estimates of premorbid Intelligence. Columbia.

Kinsella, G. I., Prior, M., \& Sawyer, M. (2007). Predictors and indicators of academic outcome in children 2 years following traumatic brain injury. Journal of the International Neuropsychological Society, 608-616.

Kinsella, G. J. (1998). Assessment of Attention Following Traumatic Brain Injury: A review. Neuropsychological Rehabilitation. 


\section{Feasibility of Home-Based Attention Retraining On People with Mild and Moderate Traumatic Brain Injury}

Kolur, U., Rao, S. L., CHandramouli, B. A., \& Thennasuru, K. (2004). The NIMHANS Neuropsychology Battery for Children. Bangalore: NIMHANS Deemed Univseristy .

Kreutzer, J. S., Gervasio, A. H., \& Camplair, P. S. (n.d.). Primary caregiver's psychological stauts annd family functioning after TBI. Brain Injury1994.

Lezak, M. D. (1995). Neuropsychological Assessement. New york: Oxford University press.

Managels, J. A., Craik, F., Levine, B., \& Schwartz, M. (2002). Effects of divided attention on episodic memory in chronic TBI: a function of severity and strategy. Neuropsychologia, 2369-2385.

Marsh, N. V., Kersel, D. A., \& Havill, J. H. (1998). Carehiver burden at 1 year follwoing severe TBI. Brain Injury, 1045-1059.

Mateer, C. A. (2000). Attention; Neuropsycholgocal managemnet of mTRI. New York: Oxford univeristy Press. Mateer, C. M., \& Mapou, R. L. (2003). Understanding, evaluating and managing attention disorders after traumatic brain injury. Journal of Head Trauma Rehabilitation,, 1-16. Matlin, M. W. (1983). Cognition. New York: Renehart and Winston.

McAvince, L., O'Keeffe, F., McMackin, D., \& Robertson, I. H. (2005). Impaired sustained attention and error awareness in truamtic brain injury: Implications for insight. Neuropsychological Rehabilitaion: An International Journal, 569-587.

Mohan, R., Rajeswaram, J., Pal, P. K., Chandran, V., \& Kandave, T. (2014). Neuropsychological Profile, Quality of Life and Associated Psychiatric Symptoms in patients with Essential Tremor. Psychology 7Psychotherapy.

Parasuraman, R., Muter, S. A., \& Molloy, R. (1991). Sustained attention following closed head injury. Jounral of Clinical an Experiemental Neuropsychology, 789-811.

Park, N. W., Moscovitch, M., \& Robertson, I. h. (1999). Divided attention impairment after TBI. Neuropsychologia, 1119-1133.

Parker, T., Ostering, L., Donkelaar, P., \& Chou, L.-S. (2005). The effect of didvide attention on gait stability following conscussion. Clinical Biomechanics, 389-395.

Patel, A., \& Kharshiing, K. D. (2014, June). Attention, Verbal Learning and memeory deficits in Somatization Disorder: A Pilot Study. International Jounral of Applied Presearch and Studies, 3(6). Ponser, M. I., \& Petersen, S. E. (1989). The Attention System of the Human Brain.

Powell, J., Morgan, J., \& Greenwood, R. (1996). Motivational Defivits after brain injury: effects of bromocriotine in 11 patients. Journal of Neurology, Neurosurgery and Psychiarty, 416-421.

Prasad, K. (1996). The Glosgow Coma Scale: a critical apparias of the clinimetric properties. Jounal of Clinical epidemiology, 755-763.

Rao, S. L., Subbakrishna, D. K., \& Gopalumar, K. (2004). NIMHANS Neuropsychologu Battery. Bangalore: NIMHANS Publications.

Raz, A. (2004). Attwntion. in Encyclopedia of applied psychology. Oxford: Oxford Inc.

Robertson, I. h., Manly, T., Andrade, J., Baddeley, B. T., \& Yiend, J. (1997). Performance correlates of everyday attentional failures in TBI and normal subjects. Neuropsychologia, 747-758.

Sarter, m., Givens, B., \& Bruno, J. (2000). The cognitive neuroscience of sustained attention: where top-down meets bootom up. Brain Research Reviews.

Seema, M., \& Rao, S. L. (1994). Divided attention in head injury. NIMHANS Jounral, 157-162.

(c) The International Journal of Indian Psychology, ISSN 2348-5396 (e)| ISSN: 2349-3429 (p) | 88 


\section{Feasibility of Home-Based Attention Retraining On People with Mild and Moderate Traumatic Brain Injury}

Shames, J., Treger, I., \& Ring, H. (2007). Return to work folloring traumatic brain injury: trends and challenges. Disability and Rehabiliation, 1387-1395.

Shukla, D., \& Devi, I. B. (2010). Mild traumatci barin injuries in adults. Jounral of Neuroscinece rural practce, 82-88.

Sohlberg, M. M., \& Mateer, C. A. (1987). Effectiveness of an Attention-Training Program. Journal of Clinical and Experimental Neuropsychology, 117-130.

Sohlberg, M. M., \& Mateer, C. A. (2008, Januvary 04). Effectiveness of an attention training program. 117 -130. Sohlberg, M., \& McLaughin, K. (2000). Evaluation of Attention Process Training and Brain Injury. Journal of Clinical and Experimental Neuropsychology, 656-676.

Sohlherg, M. (n.d.). Evaluation of Attention Process Training and Brain Injury Education in Persons with Acquired Brain Injury. 656-676.

Strub, R. L., \& Black, W. F. (2003). The Mental Status Examination in Neurology. Noida: Gopsons Papers.

Stuss, D. T., Stethem, L., Hugenholtz, H., \& Picton, T. (1989). Reaction time after head injury: fatigue, divided and focused attention, and consistency of performance. Jounral of Neurosurgery, 742-748.

Stuss, D., \& Ely, P. (1985). Subtle Neuropsychological Defiects in Patients with Good Recovery after Closed Head Injury. Neurosurgery.

Tsaousides, T., \& Gordon, W. A. (2009). Cognitive rehabilitiation following traumatic brain injury: Assessment to treatment. Journal of Medicine, 173-181.

Upadhyay, D. (2008). Cognitive functioning in TBI patients: A review of literature. MiddleEast Journal of Scientific Research, 120-125.

Wells, R., Dywan, J., \& Dumas, J. (2005). Life satisfaction and distress in family caregivers as related to specific behavioural changes after traumatic brain injury. Brain Injury, 1105-1115.

Whyte, J., Polansky, M., Fleming, M., \& Coslett, B. H. (1995). Sustained Arousal and Attention after traumatic brain injury. Neuropsychologia, 797-813.

Zasler, N., \& Katz, D. (2001). Brain injury medicine: Principles and Practice.

\section{Appendix \\ Information Letter and Consent Form \\ Study Title: Feasibility of Home based Attention Retraining on People with Mild Traumatic Brain Injury \\ Research Investigator \\ Name : Aleena Maria Sunny \\ Email : aleena_sunny@yahoo.com \\ Phone : : +919562240588}

This letter is an invitation to consider participating in a study I am conducting as part of my Post Graduation degree under the Department of Psychology at the Tata Institute of Social Science under the supervision of Mrs. Rekha Bos. 


\section{Feasibility of Home-Based Attention Retraining On People with Mild and Moderate Traumatic Brain Injury}

The purpose of the study is to check the feasibility of home based attention retraining on people with mild traumatic brain injury. I hope that the information we get from doing this research will help us better understand the study. There are no identified risks fromparticipating in this research. Participation in this research is completely voluntary and you may refuse to participate without consequence. Even if you agree to be in the study you can change your mind and withdraw at any time. You will receive no compensation for participating in the research study. The data collected from this study will be strictly held confidential.

Thank you for your consideration. Your help is greatly appreciated.

[Your signature below indicates that you have read the above information and have agreed to participate in the study "Feasibility of Home based Attention Retraining on People with Mild Traumatic Brain Injury”.

Name

Signature

Date

\section{Socio-demographic Performa}

Name:

Sex: M/F

Age:

Contact no:

Education:

illiterate/primary/middle/highschool/intermediate/graduate/postgraduate/professional

Occupation: unemployed/unskilled/semi-skilled/skilled/clerical or shop owner or farmer/semi/professional

Diagnosis: Traumatic Brain Injury (Mild/moderate/severe/coma) Brain area of injury : Frontal/ Temporal/Parietal/Occipital

How to cite this article: A M Sunny (2016), Feasibility of Home-Based Attention Retraining On People with Mild and Moderate Traumatic Brain Injury, International Journal of Indian Psychology, Volume 3, Issue 4, No. 75, ISSN:2348-5396 (e), ISSN:2349-3429 (p), DIP:18.01.046/20160304, ISBN:978-1-365-50727-4 